[Aus der Universitäts-Augenklinik zu Halle a. S.]

\title{
Ein Fall von ungewöhnlicher Hornhauterkrankang bei Chorea minor untersucht mit dem Abderhaldenschen Dialysierverfahren.
}

\author{
Von \\ E. v. Hippel \\ in Halle.
}

\section{Die folgende kurze Mitteilung hat zunächst nur kasuistisches Interesse.}

Der 12 jährige Schüler E. I. wurde mir von meinem früheren Assistenten Dr. Windrath-Weissenfels am 23. VII. 1913 zur Konsultation zugefuhrt.

Dieser hatte den Patienten am 25. VI. zum ersten Mal untersucht und überliess mir folgende Notizen.

Anamnese: Ein Bruder im Alter von 15 Jahren an Schwindsucht gestorben, zwei Angehörige der Mutter ebenfalls. Eltern gesund, Lues negiert (Wassermann negativ). Patient hat in letzter Zeit täglich in der Saale gebadet, viel unter Wasser geschwommen. Vor einigen Tagen soll ihm ein Junge mit einer aus dem Boden gerissenen Pflanze ins Gesicht geschlagen haben. Seit einigen Wochen bestehen Zuckungen im Gesicht, dio an Heftigkeit zugenommen haben.

Status: Beiderseits im Pupillargebiet massenhafte punktförmige feine Epitheldefekte, Fluoreszein positiv. Conj. und Cil. Injektion. R. Pupille enger als L. R. einige hyperämische Gefässe in der Iris. R. $S=5 / 5$, L. $S=5 / 7$. Therapie: Atropin, Xeroformsalbe, warme Umsehlïge, Schwitzen. In der Folge waren manchmal Epithelbläschen zu sehen, die sehr rasch wieder verschwanden. Die Irishyperämie war bald stärker bald schwäeher.

15. VII. Immer noch Erosionen vorhanden.

23. VII. Mein Befund: Rechts leichte Cil. Injektion, Kornealoberfläche am Mikroskop nicht ganz glatt, einzelne ganz kleine Erhebungen im Epithel, darunter dem Bereich der durch Atropin gut erweiterten Pupille entsprechend eine grosse Zahl ausserordenlich dicht stehender kleinsten Knötchen ähnelnder Trübungsfleckehen von grauweisser Farbe. Randteile der Hornhaut vollkommen frei.

Sensibilität der Hornhautmitte intakt, Ablösbarkeit des Epithels ist nicht vorhanden. Keine Irishyperämie, ophthal. normal. Druck ausserordentlich niedrig (palpatorisch). 
Ein Fall von ungewöhnlicher Hornhauterkrankung bei Chorea minor usw. 247

Links: Auge völlig blass, Pupille maximal weit. Im Pupillarbereich dieselben Pünktchen wie rechts, aber ausserordentlich zart und durchseheinend, so dass gegenüber dem früheren Befund eine zweifellose Rückbildung angenommen werden muss. Epithel jetzt glatt.

24. VIII. Beiderseits $S={ }^{5}$, Augen vollkommen blass. Rechts die Trübungen noch zu erkennen, links nicht mehr. Zuckungen im Gesicht zeitweise sehr heftig.

8. IX. Trübungen zarter. 3. X. nicht mehr zu sehen.

1. XI. Zuckungen haben nachgelassen, treten kaum mehr auf.

27. I. 1914. Völlig normaler Befund in jeder Hinsicht.

Eine von mir veranlasste Untersuchung durch Herm Kollegen Mohr am 4. VIII. 1913 ergab keinen Anhaltspunkt für eine gröbere Störung der inneren Sekretion. Thymus im Röntgenbild nachweisbar, aber mit Rücksicht auf das Alter nicht als hyperplastisch anzusehen. Kein ausgesprochener Status lymphaticus. Blutbefund normal. Diagnose: Typische Chorea minor.

26. 27. VII. 1913 AbderhaIdenscher Versuch $1,5 \mathrm{ccm}$.

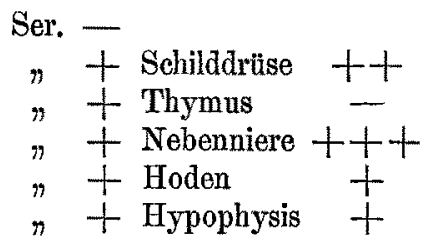

$\mathrm{Zu}$ diesem auffallenden Ergebnis, das natürlich an einen Versuchsfehler denken lässt, bemerke ich ausdrücklich, dass ein anderes Serum, das am gleichen Tag mit denselben Organen angesetztwurde, nur Thymus abbaute, also geradedasjenige Organ, das in diesem Versuch nicht angegriffen wurde. (Zuverlässigkeitsprobe.)

Am 1.|2. XI. 1913 warde ein zweiter Versuch angesetzt, leider hatte Dr. Windrath nur so wenig Blut entnehmen können, dass ich bloss Schildarüse und Nebenniere kontrollieren konnte. $1,5 \mathrm{ccm}$ :

Ser.

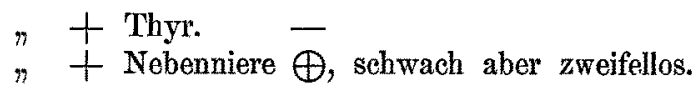

Der Versuch lässt also wenigstens das eine exkennen, dass das Serum ganz verschieden reagierte zu der Zeit, wo die Augenerkrankung und die Chorea auf der Höhe standen, und anderseits, als die erstere geheilt, dieletzterenahezu geschwunden war.

Wenn man die beschriebene Hornhauterkrankung mit bekannten Bildern zusammenbringen will, so dürfte sie am ersten der Keratitis punctata superficialis zuzurechnen sein, für die ja eine sichere Ätiologie nicht bekannt ist. Für die knötchenförmige Horn- 
248 E. v. Hippel, Ein Fall von ungewöhnlicher Hornhauterkrankung usw.

hauttrübung hat ja $\mathrm{Fuchs}$ angegeben, dass man künftig auf Störungen der Schilddrüsenfunktion achten solle. Er führt auch eine Beobachtung an von Trübung und Verdickung der Hornhaut eines mit Thyreoidin gefütterten Hundes.

I gersheimer hat ein ähnliches Resultat gehabt: Ein vom 10. VI. 1907 ab mit täglich 10 Thyreoidintabletten gefütterter Hund zeigte am 4. VII. 1907 zum erstenmal an beiden Augen eine parenchymatöse Hornhauttrübung, die sich ganz allmählich und nur wenig vergrösserte. Am 6. IX. wurde rechts eine Veränderung insofern festgestellt, als die Gruppe von parenchymatös gelegenen Fleckchen in eine mehr bröcklige Masse umgewandelt war, die etwas über das Niveau der Cornea vorragte und zu der Gefässe hinzogen.

In experimentellen Untersuchungen über SchilddrüsenExstirpation wird gelegentlich von Hornhauttrübungen und Geschwüren berichtet; es lohnt sich aber nicht, die Arbeiten hier näher zu besprechen, da die ganze Frage noch durchaus nicht geklärt ist und meine kleine Mitteilung nur das Interesse für die genauere Untersuchung solcher seltenen Fälle wecken soll. 